

\title{
Rapid onset cancer of the cervix
}

The Advisory Committee on Cancer Registration ${ }^{1}$ reported recently that "the results of treatment as measured by survival are generally little better than they were 20 years ago." Certainly screening for early uterine cervical cancer, with improved techniques in treatment such as the use of the colposcope and the laser, offers a much preferable alternative to the treatment of invasive disease. Yet the effect of extensive screening for early cervical cancer in Britain has been disappointing in comparison with some countries. Canada, ${ }^{2}$ Finland, ${ }^{3}$ and some regions of Scotland ${ }^{4}$ have all reported falls in mortality, but in England and Wales there has actually been a rise, especially in young women under $35 .{ }^{5}$

One possible factor in the continuing occurrence of deaths from cervical cancer might be a more rapid progression from cervical interepithelial neoplasia grade 3 to invasive cancer than the generally accepted 15 to 20 years interval. The age of presentation of cervical interepithelial neoplasia grade 3 has become younger over the past two decades, possibly associated with a general change in social mores-the advent of the contraceptive pill allowing girls to have greater sexual freedom and the earlier maturity of girls. There is no evidence ${ }^{6}$ to suggest that the contraceptive pill causes cancer; indeed, the girls who develop cervical interepithelial neoplasia grade 3 at an early age typically become pregnant before using it. Though these girls have early intercourse and teenage pregnancies, those dying from invasive disease at an age of under 25 would need to have had rapidly progressive disease.

A recent report from Dunn in California ${ }^{7}$ found that $29 \%$ of women who developed invasive cervical cancer between 1970 and 1974 had had recent negative cytological screening. In Aberdeen, ${ }^{8}$ while $90 \%$ of women who develop invasive cancer have never had a smear, $2 \%$ had had a smear within the preceding five years. Berkeley ${ }^{9}$ identified 10 patients with negative Papanicolaou tests within a year of presentation with advanced cervical cancer. Clarke ${ }^{10}$ had 60 patients with invasive cancer who had at least one smear that had been classified as less than malignant within the previous six years. Albert ${ }^{11}$ has produced an elaborate statistical model which, when based on the figures from the British Columbian screening programme, suggests that the average annual transition period from cervical interepithelial neoplasia grade 3 to occult invasive cancer is $20-30$ years but that a few patients will progress to the invasive stage in one year or less.

If even small groups truly have such a short incubation period the interval between smears in a screening programme may well require to be less than that advocated. Nevertheless, the bulk of cytological $^{12}$ and epidemiological ${ }^{13}$ evidence suggests that progression from cervical interepithelial neoplasia grade 3 to occult invasive takes over 10 years. Most gynaecologists have had patients with cervical interepithelial neoplasia grade 3 who for various reasons were undertreated and who progressed to invasive cancer. Burghardt ${ }^{14}$ found that this took from five to 21 years from the initial treatment. Spriggs ${ }^{15}$ followed untreated cases for over five years, and none had died.

On review of the apparently rapidly progressing cases in Berkeley's and Clarke's series five out of 10 and 12 out of 24 respectively had had the diagnosis missed on screening. The false-negative rate in reporting varies considerably ${ }^{16}$ but may be as high as $20 \%$ in some centres. Good interpretation by highly qualified personnel is very important. Different types of laboratory should not be assumed automatically to obtain results that are strictly comparable ${ }^{17}$; any deficiencies need to be identified and remedied.

Clinical invasive lesions are known sometimes to give dirty, blood-stained smears which contain only scanty and normal cells. ${ }^{1819}$ The cytological findings are truly negative, owing to the presence of the lesion, and all doctors taking smears should be aware of this pitfall. If the appearance of the cervix suggests a malignant lesion the patient should be immediately referred for further investigation in spite of a negative cytological report. This anomaly accounts for some of the apparently rapidly progressing cases.

The falls in mortality in the well-documented programmes mentioned suggest that not only is screening effective but that it is effective when smears are taken at intervals of three to five years. In all of these the incubation period appears to be sufficiently long to allow five years to elapse between smears. Patients with apparently rapidly progressive lesions had generally had only one previous smear. Two satisfactory smears with a five-year interval provide a very considerable degree of protection.

This "rapid onset" theory deserves serious attention; in a few patients the disease does progress abnormally quickly. Nevertheless, a woman with a healthy cervix having a good satisfactory smear which contains only normal cells may begin to develop abnormal cells the next day, though all the evidence suggests that five years later the lesion will be at the in-situ 
stage and eminently curable. That picture does not entirely explain the deaths in very young women under 25 years of age. Until a close study of their case histories has been carried out and the histological diagnosis of tumour type is known, however, it would be premature to complicate screening policies to try to anticipate the possibility of a rapidly progressing variant of cervical cancer.

\section{J ElizABEth MACGREgor}

Senior Lecturer and Honorary Consultant in Pathology,

University of Aberdeen,

Foresterhill,

Aberdeen AB9 2ZD

${ }^{1}$ Advisory Committee on Cancer Registration. Report of Advisory Committee on Cancer Registration. Cancer registration in the 1980s, England and Wales. London: HMSO, 1981:39. (Acheson Committee.)

${ }^{2}$ Miller AB, Lindsay J, Hill GB. Mortality from cancer of the uterus in Canada and its relationship to screening for cancer of the cervix. Int $\mathcal{f}$ Cancer 1976;17:602-12.

${ }^{3}$ Hakama M, Räsänen-Virtanen V. Effect of a mass screening program on the risk of cervical cancer. Am $\mathcal{F}$ Epidemiol 1976;103:512-7.

4 Macgregor JE, Teper S. Mortality from carcinoma of cervix uteri in Britain. Lancet 1978;ii:774-6.

${ }^{5}$ Adelstein AM, Husain OAN, Spriggs AI. Cancer of the cervix and screening. Br Med f $1981 ; 282: 564$

6 Vessey MP, McPherson K, Yeates D. Mortality in oral contraceptive users. Lancet $1981 ; \mathrm{i}: 549-50$.

${ }^{7}$ Dunn JE, Schweitzer V. The relationship of cervical cytology to the incidence of invasive cervical cancer and mortality in Alameda County, California, 1960 to 1974. Am f Obstet Gynecol 1981;139:868-76.

${ }^{8}$ Macgregor JE. Cancer of the cervix and screening. Br Med f $1981 ; 282$ : 734.

9 Berkeley AS, Li Volsi VA, Schwartz PE. Advanced squamous cell carcinoma of the cervix with recent normal Papanicolaou tests. Lancet 1980 ;ii : 375-6.

${ }^{10}$ Clarke EA, Anderson TW. Implications of cervical dysplasia. Lancet $1980 ; 1: 1420$.

11 Albert A. Estimated cervical cancer disease state incidence and transition rates. $\mathcal{F} N C I$ 1981;67:571-6.

${ }^{12}$ Richart RM, Barron BA. A follow-up study of patients with cervical dysplasia. Am $\mathcal{F}$ Obstet Gynecol 1969;105:386-93.

13 Fidler HK, Boyes DA, Worth AJ. Cervical cancer detection in British Columbia. Fournal of Obstetrics and Gynaecology of the British Commonwealth $1968 ; 75: 392-404$.

14 Burghardt E, Holzer E. Treatment of carcinoma in situ. Evaluation of 1609 cases. Obstet Gynecol 1980;55:539-45.

15 Kinlen LJ, Spriggs AI. Women with positive cervical smears but without surgical intervention. A follow-up study. Lancet 1978;ii:463-5.

${ }^{16}$ Husain OAN, Butler EB, Evans DMD, Macgregor JE, Yule R. Quality control in cervical cytology. $\mathcal{F}$ Clin Pathol 1974;27:935-44.

${ }^{17}$ Anonymous. Quality of performance in pathology laboratories. Lancet $1981 ; 1: 599$.

18 Macgregor EJ. Misleading exfoliative cytology (titled incorrectly Drug therapy and cancer diagnosis). Br Med $\mathcal{F} 1964 ; \mathrm{ii}: 754-5$.

19 Prendiville W, Guilleband J, Bamford P, Beilby J, Steele SJ. Carcinoma of cervix with recent normal Papanicolaou tests. Lancet 1980;ii:853-4.

\section{Career guidance by computer}

In the past 10 years or so a complex organisation has grown up to oversee doctors' training needs both in hospitals and latterly in general practice. After preregistration experience, which is the responsibility of the medical school, posts suitable for general professional training (senior house officer and registrar) are approved by the royal colleges and faculties, and the senior registrar posts suitable for higher professional training are dealt with by joint committees on higher training on the recommendation of specialist advisory committees, which visit posts. Unfortunately, inspection and assessment take time, at present posts are approved for a maximum of five years, and the approving bodies differ in the way they carry out their functions. As a result co-ordinating information has proved difficult and the whole exercise is expensive. What information does become available is eventually disseminated to the DHSS, the councils for postgraduate education, regional postgraduate organisations, and area health authorities and districts. A recent request from the General Medical Council to regions for information on the training role of senior house officer and registrar posts, however, showed how difficult it was to discover which posts had been visited and approved or turned down.

Some form of flexible and easily accessible information service is needed, so that people such as postgraduate deans and clinical tutors can provide up-to-date information about training not only for statutory bodies but also-and more important-for junior doctors who come to them in increasing numbers for advice. A valuable report (Training doctors: a study of information needs) by J C C Smith, commissioned by the Chief Medical Officer to the Department of Health, has been circulated recently though not published. This looks at the feasibility of a co-ordinated system based on regions using computers to provide instant information about training posts throughout the country. The regional computer systems that already exist are concerned largely with manpower, planning, and payrolls. The only system purely devoted to careers is the Medical Education Information and Career Service (MEDICS) developed by the South-west Thames region. Though funds have been provided by the region, the system itself is run from the regional dean's office of the British Postgraduate Medical Federation and such is its flexibilityit relies on a microcomputer with printers and visual display units-that it can be used on the spot and has spare capacity which could be extended to include all four Thames regions. Its value has been shown in the exercise to establish the role of training posts referred to above.

Smith emphasises that service and training needs cannot be separated-indeed they should not be-and the DHSS already publishes annual manpower statistics from which information can be obtained about career opportunities in the different specialties. Unfortunately these appear only annually, and they are presented in indigestible tables, difficult to interpret. Smith proposes a Medical Manpower and Training Information System (MATRIS) which would eventually link regional and district users. He rejects the mainframe computer system in operation at present in favour of free-standing, useroriented systems based on 16-bit microprocessors. Their advantages are flexibility; accessibility; ease of use with minimal training, cheapness, and availability of hardware; and initially at least considerable spare capacity. Since it will take time to develop a national network he suggests a pilot study which would be particularly concerned with validating methods for capturing data. DHSS finance should surely be available for one or more such studies; the cost does not look formidable.

Doctors in training need to know where approved posts are available in different specialties and different parts of the country; expected future vacancies; how long people are staying in various grades in the different specialties; and what are the long-term prospects for consultant appointments. Answers to these and many other questions could be provided reasonably soon and probably quite cheaply. A computer-based system would also help the authorities by providing printouts of posts that require reinspection, rotation of senior registrars, years of service in different grades and specialties, and so on. In the fullness of time such a system might even be able to contribute to correcting the imbalance between junior and senior medical staff.

Alex Paton

Postgraduate Dean,

North-east Thames Region,

London NW1 $5 \mathrm{HD}$ 